\title{
CASE-BASED LEARNING OPEN When should I be considering home oxygen for my patients?
}

\author{
Jay Suntharalingam ${ }^{1}$, Sabrine Hippolyte ${ }^{2}$, Vikki Knowles ${ }^{3}$, Daryl Freeman ${ }^{4}$, Irem Patel ${ }^{5}$ and Maxine Hardinge ${ }^{6}$
}

The ability to provide oxygen in a patient's home can offer enormous benefits, including improvements in life expectancy when given in the appropriate setting. Confusingly, however, home oxygen is available in many forms, including long-term oxygen therapy (LTOT), ambulatory oxygen therapy (AOT), palliative oxygen therapy (POT) and short-burst oxygen therapy (SBOT)-each with varying degrees of supporting evidence. The British Thoracic Society (BTS) has recently published new guidance on home oxygen therapy, after collating the available evidence. This article aims to summarise those guidelines, focusing on who should and should not be considered for oxygen therapy. Although the BTS guidelines target a UK audience, many of the principles covered below are applicable internationally, even if the availability of certain oxygen modalities and supporting service arrangements may vary between different healthcare systems.

npj Primary Care Respiratory Medicine (2016) 26, 15074; doi:10.1038/npjpcrm.2015.74; published online 7 January 2016

\section{CLINICAL SCENARIO 1: A 63-YEAR-OLD MAN WITH MODERATE COPD-IS HOME OXYGEN INDICATED?}

A 63-year-old retired shopkeeper attends for his annual chronic obstructive pulmonary disease (COPD) review. He was diagnosed 3 years ago following a 40 pack-year history of smoking, and since then he has been managed with tiotropium. His exercise tolerance was initially reasonable, but it has recently fallen to $410 \mathrm{~m}$. As a result, he has lost confidence and become less independent. One of his friends suggested that he ask for home oxygen to help with his symptoms. His spirometry shows moderate airflow obstruction (FEV $1.5 \mathrm{I}$ or $51 \%$ predicted, FVC $2.7 \mathrm{I}$ or $91 \%$ predicted and $\mathrm{FEV}_{1} / \mathrm{FVC}$ ratio $56 \%$ ). His oxygen saturation is $96 \%$ on air.

\section{SHOULD OXYGEN BE USED IN BREATHLESS PATIENTS, IN THE ABSENCE OF HYPOXAEMIA?}

This is a typical COPD presentation, with first symptoms occurring in late adulthood following a significant smoking history and accompanied by supporting changes on spirometry. In this context, patients often experience frightening and debilitating breathlessness. Of note, his saturations remain well preserved on air (i.e., > 92\%), demonstrating that he is not hypoxaemic at rest. What is the role, if any, of oxygen in this setting?

The British Thoracic Society (BTS) oxygen guideline summarises the evidence for, and provides recommendation on, the different options for home oxygen therapy (listed in Table 1). ${ }^{1}$ Box 1 summarises the key recommendations from the guideline. Previously, both short-burst oxygen therapy (SBOT) and ambulatory oxygen therapy (AOT) have been considered for nonhypoxaemic patients with disabling breathlessness. The evidence to support this, however, is limited.

\section{SHORT-BURST OXYGEN THERAPY}

SBOT refers to the intermittent use of oxygen for short periods (typically 10-20 min) immediately before or after exercise, with the intention of relieving breathlessness and speeding up recovery. Although SBOT has been offered for many years, several recent studies show a lack of efficacy in terms of improving exercise tolerance, recovery time or breathlessness. ${ }^{2-5}$ Many of these studies were randomised and double-blinded, using air and/or fan therapy as comparators. Studies included both hypoxaemic and non-hypoxaemic patients but failed to show benefit in either group. Given these data, the guidelines conclude that there is no therapeutic role for SBOT in either hypoxaemic or non-hypoxaemic COPD patients.

\section{AMBULATORY OXYGEN THERAPY}

AOT is the use of oxygen delivered via a portable cylinder during exercise and other exertion, such as activities of daily living. Historically, AOT has been used in mobile patients who are not hypoxaemic at rest but who desaturate on exercise, with the aim of improving oxygen saturations and exercise capacity.

A number of lab-based studies suggest that AOT may improve certain physiological parameters during supervised exercise. ${ }^{6}$ However, longer-term 'real-life' clinical trials of AOT used at home/community suggest that AOT offers no substantial long-term benefits and is often under-utilised. ${ }^{7,8}$ Appropriate use of domiciliary oxygen relies on successful patient engagementthis is a particular issue with AOT where patients can feel self-conscious leaving the house with visible, and often heavy, oxygen equipment. Given the lack of long-term data, there is therefore insufficient evidence to support routine use of AOT in COPD patients who do not fulfil the criteria for LTOT.

Despite the lack of evidence, it is recognised that a small proportion of patients with debilitating breathlessness and reduced exercise capacity due to hypoxaemia may engage with using AOT and may benefit from it. This is particularly relevant in other non-COPD chronic lung diseases (e.g., pulmonary fibrosis) in which patients more often tend to desaturate substantially on exercise. The guidelines therefore allow motivated

\footnotetext{
${ }^{1}$ Respiratory Department, Royal United Hospitals Bath NHS Foundation Trust, Bath, UK; ${ }^{2}$ Respiratory Department, Respiratory SpR, Royal Brompton Hospital, London, UK; ${ }^{3}$ Guildford and Waverley Clinical Commissioning Group, Guildford, UK; ${ }^{4}$ Mundesley Medical Centre, NHS England, Midlands and East, Norfolk, UK; ${ }^{5}$ Respiratory Department, Integrated Care, Kings Health Partners, King College London School of Medicine, London, UK and ${ }^{6}$ Respiratory Department, Churchill Hospital, Oxford, UK.

Correspondence: J Suntharalingam (jay.suntharalingam@nhs.net)

Received 29 August 2015; accepted 8 September 2015
} 
Table 1. Abbreviations for types of oxygen therapy

\begin{tabular}{|c|c|}
\hline Abbreviation & Definition \\
\hline AOT & Ambulatory oxygen therapy: \\
\hline & The use of oxygen delivered via a portable cylinder during exercise and other exertion, such as activities of daily living \\
\hline LTOT & Long-term oxygen therapy: \\
\hline & Oxygen administered for $\geqslant 15 \mathrm{~h} /$ day for patients who are chronically hypoxaemic \\
\hline POT & Palliative oxygen therapy: \\
\hline & Oxygen to relieve dyspnoea in a life-limiting disease where all reversible causes have been treated \\
\hline SBOT & $\begin{array}{l}\text { Short burst oxygen therapy: } \\
\text { The intermittent use of oxygen for short periods (typically } 10-20 \mathrm{~min} \text { ) immediately before or after exercise, with the intention of } \\
\text { relieving breathlessness and speeding up recovery }\end{array}$ \\
\hline
\end{tabular}

Box 1 Summary of key recommendations from the BTS guideline. ${ }^{1}$

- Oxygen is a treatment for hypoxaemia, not breathlessness

- Home oxygen prescriptions need specialist review-refer to your local home oxygen assessment team, rather than prescribing in primary care

- Long-term oxygen therapy (LTOT) can improve survival in stable COPD patients who remain chronically hypoxic

- Short-burst oxygen therapy (SBOT) is ineffective and should not be ordered

- Ambulatory oxygen therapy (AOT) is unlikely to provide long-term benefits in the majority of patients with exertional dyspnoea and should not be routinely ordered

- Palliative oxygen therapy (POT) is not as effective as opiates in controlling dyspnoea in life-limiting disease and should only be ordered when all other options have been explored.

patients to be considered for a trial of AOT following formal assessment by a specialist home oxygen assessment service, once all other medical interventions have been optimised. ${ }^{1}$ These patients should only continue if they can demonstrate benefit from, and good compliance with, therapy.

\section{WHAT ARE THE ALTERNATIVES TO OXYGEN THERAPY IN THIS PATIENT?}

It is important to help the patient understand why he is breathless and that oxygen is a treatment for low oxygen levels, not breathlessness. Alternative strategies for relieving breathlessness are listed in Box 2. If the patient is still smoking, then treating his tobacco dependence is paramount. Lifestyle changes, such as increasing activity levels and losing weight, can also improve breathlessness. Referral to a local pulmonary rehabilitation program is crucial, as it can improve breathlessness and exercise tolerance, as well as offer disease education and self-management skills. Ensure that his inhaled therapy is optimised by checking his inhaler technique, addressing any adherence issues and consider adding a LABA. According to availability, refer to a community respiratory team, or other specialist respiratory service, to provide ongoing support. There may be a role for specific mental health support for those with a high anxiety component or low mood. Finally, he should be put in contact with a local patient association (e.g., in the UK, BreatheEasy groups are local peer support groups sponsored by the British Lung Foundation (BLF)), which can offer further local support.

\section{WHAT IS THE ROLE OF LTOT IN COPD?}

LTOT, i.e., oxygen administered for $\geqslant 15 \mathrm{~h}$ /day for patients who are chronically hypoxaemic, remains the most evidence-based form of

Box 2 Strategies for relieving breathlessness in people with COPD
Options other than oxygen
- Smoking cessation
- Lifestyle changes (e.g., increase in activity levels, weight loss)
- Pulmonary rehabilitation
- Optimisation of inhaler therapy-choice of inhaler and
- inhaler technique
- Refer to the community respiratory team
- Put into contact with a patient support group

domiciliary oxygen in use. The evidence for LTOT centres around two landmark RCTs carried out in the 1980s, which both showed a survival benefit in COPD patients that only became apparent after several years of use. ${ }^{9,10}$ At present, smoking cessation and LTOT are the only two interventions known to improve survival outcomes in COPD.

\section{CLINICAL SCENARIO 1: THE STORY CONTINUES}

The same gentleman has been under your care for a further 5 years. During this time, he has become much more limited and now has an exercise tolerance of $100 \mathrm{~m}$. He has experienced several exacerbations and has been admitted twice in the last year. He attends for a routine review 3 weeks after his most recent admission. His spirometry has continued to deteriorate $\left(\mathrm{FEV}_{1} 0.6 \mathrm{I}\right.$ or $23 \%$ predicted) and he is now hypoxaemic (saturations $91 \%$ on air). Unfortunately, he has also started smoking again

\section{WHEN AND HOW SHOULD I SCREEN PATIENTS FOR LTOT?}

Given the evidence for LTOT, it is important that potential candidates be screened and referred in a timely manner. It is therefore recommended that all patients be screened within their annual COPD assessment. Patients whose resting saturations are $\leqslant 92 \%$ on air during a period of stability should be referred to their local home oxygen service for a formal assessment with arterial blood gas sampling. LTOT should only be prescribed by specialists after a comprehensive review, and it is not something that should be initiated in primary care.

The need to identify patients early must be balanced against the potential for overprescribing LTOT to 'unstable' patients who have not yet fully recovered from an exacerbation. ${ }^{11}$ Patients should therefore not be screened for LTOT until they are $\geqslant 8$ weeks clear of an exacerbation-thus, our patient would need to be rescreened in 5 weeks' time. 


\section{LTOT ASSESSMENT AND ADMINISTRATION}

Oxygen is a medicine used to treat hypoxia. Similar to any drug, the appropriate dose for an individual patient needs to be considered, and it can vary. Patients referred to a home oxygen service will undergo a comprehensive assessment including checking blood gases that will determine whether oxygen is required, and at what level it should be administered. The home oxygen assessment service will ensure that the patient does not become hypercapnic on oxygen and will complete the appropriate documentation (e.g., in the UK a Home Oxygen Order Form or HOOF), prescribing the required flow rate for the patient's LTOT. This is typically delivered via nasal prongs for $\geqslant 15 \mathrm{~h} /$ day through an oxygen concentrator installed in the patient's home. Patients who use their oxygen for less than this amount are unlikely to see any survival benefits. Those who are mobile outdoors may be offered AOT in addition to LTOT to enable them to accumulate sufficient hours of LTOT usage per day, ${ }^{12}$ and will undergo further assessment to determine whether a higher flow rate is needed during exercise.

The home oxygen assessment team will also educate the patient and carers and work with the home oxygen supplier to make sure that a comprehensive risk assessment has been completed in the patient's home. Patients will be informed of their responsibility to use oxygen safely, including abstinence from smoking (at the very least while using the oxygen). The home oxygen team should also identify patients at risk of harm from excessive oxygen, for example, during an ambulance transfer, and ensure that care plans and/or alerts are in place to address this.

Commencing LTOT is a key milestone in any patient's disease trajectory. Not only will the treatment have a huge impact on their life and that of their carers but the need for LTOT also signifies advanced disease-this carries advance care planning implications that may need to be considered.

\section{LTOT AND SMOKING}

It is not known whether patients who continue to smoke receive any survival benefit from LTOT. As current smoking is the main driver of premature mortality and adverse outcomes in COPD, there are theoretical and physiological reasons why these patients are unlikely to have the same benefit-however, $33-48 \%$ of patients included in the original landmark LTOT trials were current smokers at the time of recruitment. Notwithstanding any possible lack of benefit, the main concern over current smoking and LTOT is the potential for great harm, not only to the individual but also to carers, co-habitants and others. ${ }^{13}$ Up to $25 \%$ of all oxygen- and smokingrelated domestic fires result in death and $33 \%$ in serious injury. ${ }^{14}$

The current guideline leaves the final decision regarding oxygen prescription with individual clinicians, but it does offer practical advice for home oxygen services around risk estimation and mitigation. Just as prescriptions of nephrotoxic drugs are modified in patients with renal impairment because of the potential for harm, so any decision on home oxygen prescription needs to balance the potential clinical benefit against the risk of harm on a case-by-case basis.

\section{CLINICAL SCENARIO 2: A WOMAN WITH ADVANCED METASTATIC BREAST CANCER WHO IS BREATHLESS-IS HOME OXYGEN APPROPRIATE?}

A 58-year-old office worker has been under an oncologist for 8 years with breast cancer. Her disease has repeatedly progressed despite several chemotherapy regimens. She now has advanced disease with pulmonary metastases and is under supportive care only. Her husband contacts you shortly after her last oncology assessment to report that she now has debilitating breathlessness. When you visit her she is breathless on minimal exertion but still has a well-preserved saturation ( $94 \%$ on air). She asks whether she should have home oxygen.

\section{IS THERE A ROLE FOR OXYGEN IN NON-HYPOXAEMIC PATIENTS WITH ADVANCED DISEASE WHO ARE BREATHLESS?}

Assuming that the oncology team has excluded all treatable pathologies (e.g., infection, $\mathrm{PE}$, pulmonary embolism, anaemia), the aim of management is to offer symptom control in a minimally intrusive way. In this setting, is there a role for palliative oxygen therapy (POT)-i.e., oxygen to relieve dyspnoea in a life-limiting disease in which all reversible causes have been treated?

A number of studies, including a large RCT, have found no symptomatic benefit in non-hypoxaemic patients from supplementary oxygen over medical air. ${ }^{15,16}$ One study, however, demonstrated that opioids can control dyspnoea more effectively than oxygen. ${ }^{17}$ Fan therapy has also been reported to be helpful. Current guidance therefore suggests that oxygen is not indicated in dyspnoeic patients with life-limiting illness who are non-hypoxaemic, and that a trial of opioids or fan therapy should be offered instead. ${ }^{1}$

\section{CLINICAL SCENARIO 2. THE STORY CONTINUES}

The same lady has remained poorly, but stable, for a further 6 weeks. A community matron routinely visits her and reports that her symptoms are unchanged but her saturations are now lower at $89 \%$ on air. Is home oxygen indicated now?

\section{SHOULD POT BE CONSIDERED IN HYPOXAEMIC PATIENTS?}

This lady is now hypoxaemic, presumably because of disease progression. Assuming that there is no evidence of any new treatable pathology, should oxygen be considered now?

Unlike LTOT, the aim of management here is simply to provide symptom relief, not to improve life expectancy. With this in mind, the available evidence, albeit limited, suggests that POT does not confer any symptomatic benefit over air in hypoxaemic patients. ${ }^{18}$ Again, opioids appear to be more effective at improving symptoms in this setting. ${ }^{17}$ Many non-pharmacological-based interventions can also help, from the simple use of room/ handheld fans to positioning and reassurance.

POT should therefore not be offered routinely in either hypoxaemic or non-hypoxaemic patients with life-limiting disease. POT may, however, be considered occasionally in either patient group by a specialist palliative care team when intractable breathlessness persists and all other treatments have been tried. The response to POT should be formally assessed, and therapy should be discontinued if no symptomatic relief is obtained.

\section{SUMMARY}

This article has demonstrated that oxygen should be considered a treatment for hypoxaemia, not breathlessness, and thus it has little role in the non-hypoxaemic patient. Conversely, robust evidence exists for the use of LTOT in chronically hypoxaemic patients where it confers a significant long-term survival benefit. These patients need specialist assessment and follow-up by a local home oxygen assessment service. There is little evidence to support the routine use of other forms of oxygen such as SBOT, AOT or POT in patients who do not qualify for LTOT.

\section{CONTRIBUTIONS}

JS wrote the initial draft of the paper. $\mathrm{MH}, \mathrm{IP}, \mathrm{SH}, \mathrm{VH}$ and DF all subsequently added significant contributions to the final document 


\section{COMPETING INTERESTS}

The authors declare no conflict of interest.

\section{FUNDING}

The authors declare that no funding was received.

\section{REFERENCES}

1. Hardinge, M. et al. British Thoracic Society guidelines for home oxygen use in adults. Thorax 70(Suppl 1): i1-i43 (2015).

2. Stevenson, N. J. \& Calverley, P. M. A. Effect of oxygen on recovery from maximal exercise in patients with chronic obstructive pulmonary disease. Thorax 59, 668-672 (2004).

3. Lewis, C. A., Eaton, T. E., Young, P. \& Kolbe, J. Short-burst oxygen immediately before and after exercise is ineffective in nonhypoxic COPD patients. Eur. Respir. J. 22, 584-588 (2003).

4. O'Driscoll, B. R., Neill, J., Pulakal, S. \& Turkington, P. A crossover study of short burst oxygen therapy (SBOT) for the relief of exercise-induced breathlessness in severe COPD. BMC Pulm. Med. 11, 23 (2011).

5. Nandi, K. et al. Oxygen supplementation before or after submaximal exercise in patients with chronic obstructive pulmonary disease. Thorax 58, 670-673 (2003).

6. Bradley, J. M. \& O'Neill, B. Short-term ambulatory oxygen for chronic obstructive pulmonary disease. Cochrane Database Syst Rev (2005) 4, Art. No.: CD004356. doi:10.1002/14651858.CD004356.pub3.

7. Moore, R. P. et al. A randomised trial of domiciliary, ambulatory oxygen in patients with COPD and dyspnoea but without resting hypoxaemia. Thorax 66, 32-37 (2011).

8. Ringbaek, T., Martinez, G. \& Lange, P. The long-term effect of ambulatory oxygen in normoxaemic COPD patients: a randomised study. Chron. Respir. Dis. 10, 77-84 (2013).

9. Continuous or nocturnal oxygen therapy in hypoxemic chronic obstructive lung disease: a clinical trial. Nocturnal Oxygen Therapy Trial Group. Ann. Intern. Med. 93, 391-398 (1980).

10. Medical Research Council Working Party. Long term domiciliary oxygen therapy in chronic hypoxic cor pulmonale complicating chronic bronchitis and emphysema: report. Lancet 1, 681-686 (1981).
11. Guyatt, G. H. et al. A randomized trial of strategies for assessing eligibility for long-term domiciliary oxygen therapy. Am. J. Respir. Crit. Care Med. 172, 573-580 (2005).

12. Petty, T. L. \& Bliss, P. L. Ambulatory oxygen therapy, exercise, and survival with advanced chronic obstructive pulmonary disease (the Nocturnal Oxygen Therapy Trial revisited). Respir. Care 45, 204-211 (2000).

13. Centers for Disease Control and Prevention (CDC). Fatal fires associated with smoking during long-term oxygen therapy--Maine, Massachusetts, New Hampshire, and Oklahoma, 2000-2007. MMWR Morb. Mortal. Wkly Rep. 57, 852-854 (2008).

14. Ahrens, M. National Fire Protection Association 2008. Fire and Burns Involving Home Medical Oxygen. Available at http://www.nfpa.org/research/reportsand-statistics/demographics-and-victim-patterns/medical-oxygen (accessed on August 2015).

15. Currow, D. C., Agar, M., Smith, J. \& Abernathy, A. P. Does palliative home oxygen improve dyspnoea? A consecutive cohort study. Palliat. Med. 23, 309-316 (2009).

16. Uronis, H. E., Currow, D. C., McCrory, D. C., Samsa, G. P. \& Abernathy, A. P. Oxygen for relief of dyspnoea in mildly- or non-hypoxaemic patients with cancer: a systematic review and meta-analysis. Br. J. Cancer 98, 294-299 (2008).

17. Clemens, K. E., Quednau, I. \& Klaschik, E. Use of oxygen and opioids in the palliation of dyspnoea in hypoxic and non-hypoxic palliative care patients: A prospective study. Support Care Cancer 17, 367-377 (2009).

18. Philip, J. et al. A randomized, double-blind, crossover trial of the effect of oxygen on dyspnea in patients with advanced cancer. J. Pain. Symptom Manage 32, 541-550 (2006).

(c) (i) $\odot$ This work is licensed under a Creative Commons AttributionNonCommercial-NoDerivatives 4.0 International License. The images or other third party material in this article are included in the article's Creative Commons license, unless indicated otherwise in the credit line; if the material is not included under the Creative Commons license, users will need to obtain permission from the license holder to reproduce the material. To view a copy of this license, visit http:// creativecommons.org/licenses/by-nc-nd/4.0/ 